\title{
Peri-treatment change of anorectal function in patients with rectal cancer after preoperative chemoradiotherapy
}

\author{
Jin Sook Song ${ }^{1}$, In Ja Park ${ }^{2}$, Jeong Hye Kim³${ }^{3}$ Hyang Ran Lee ${ }^{1}$, Jeong Rang Kim ${ }^{1}$, \\ Jong Lyul Lee ${ }^{2}$, Yong Sik Yoon ${ }^{2}$, Chan Wook Kim², Seok Byung Lim², Chang Sik Yu ${ }^{2}$ \\ and Jin Cheon Kim² \\ ${ }^{1}$ Department of Colorectal Clinic, Asan Medical Center, Seoul, Korea \\ 2 Department of Colon and Rectal Surgery, Asan Medical Center, University of Ulsan College of Medicine, Seoul, Korea \\ ${ }^{3}$ Department of Clinical Nursing, University of Ulsan, Seoul, Korea \\ Correspondence to: In Ja Park, email: ipark@amc.seoul.kr
}

Jeong Hye Kim, email: kimjh@amc.seoul.kr

Keywords: anorectal manometry, anorectal function, preoperative chemoradiotherapy, rectal cancer

Received: March 29, $2017 \quad$ Accepted: August 15, $2017 \quad$ Published: August 27, 2017

Copyright: Song et al. This is an open-access article distributed under the terms of the Creative Commons Attribution License 3.0 (CC BY 3.0), which permits unrestricted use, distribution, and reproduction in any medium, provided the original author and source are credited.

\section{ABSTRACT}

Preoperative chemoradiotherapy (PCRT) is a standard treatment for locally advanced rectal cancer. The influence of PCRT on anorectal function has not been objectively assessed. We evaluated the short-term influence of PCRT on anorectal function in patients with locally advanced rectal cancer using anorectal manometry. We included 310 patients with locally advanced mid and lower rectal cancer who underwent PCRT from 2012 to 2015. We compared anorectal function based on anorectal manometry between before and after PCRT according to tumor location, clinical T (cT) stage, and tumor response after PCRT. Lower rectal cancer was common in the cohort of 310 patients $(n=228,73.5 \%)$. Sphincter length $(p=0.003)$ and maximal resting pressure $(p<0.001)$ increased and maximal tolerated volume ( $p$ $=0.036$ ) decreased after PCRT regardless of tumor location. Maximal squeezing pressure and rectal compliance slightly decreased, without statistical significance. Changes in manometric parameters after PCRT were not associated with changes of CT stage after PCRT. However, minimal sensory volume $(p=0.042)$ and maximal tolerated volume $(p=0.025)$ increased significantly in 143 patients $(46.1 \%)$ with changes in the distance of the cancer from the anal verge after PCRT. PCRT did not impair the overall short-term anorectal manometric parameters in patients with locally advanced rectal cancer. Further study is required to investigate postoperative anorectal function after sphincter-preserving surgery to evaluate the long-term effects of PCRT on anorectal function.

\section{INTRODUCTION}

Preoperative chemoradiotherapy (PCRT) is currently recommended as the standard treatment for locally advanced rectal cancer [1-3]. It is known to decrease local recurrence rates without increasing treatment-associated toxicity compared to postoperative adjuvant chemoradiotherapy [4-7]. In addition, PCRT has been reported to improve sphincter preservation in several studies [2, 5-7], and the introduction of PCRT has led to the greater possibility of sphincter preservation, especially in lower rectal cancer patients.

Many patients with rectal cancer wish to undergo sphincter-preserving surgery (SPS) to preserve quality of life. However, following SPS, defecation disorders such as frequent defecation, urgency, clustering, and fecal incontinence can occur, and cooperation of the rectum and anus is impaired. Therefore, anorectal function is compromised and quality of life is affected [8-11]. It is 
known that the possibility of SPS increases after PCRT, but there are conflicting opinions over whether SPS after PCRT causes more severe anorectal dysfunction than SPS. Previous studies have reported that patients with SPS after PCRT can develop fecal incontinence [3] due to anorectal functional deterioration $[1,3,12-14]$ more frequently than patients who underwent surgery alone, and that PCRT causes damage to the anal sphincter and pudendal nerve [15].

Previous studies on the influence of PCRT on anorectal function have evaluated long-term functionality after SPS [1, 3, 12-14, 16, 17]. However, it is not easy to investigate the direct effects of PCRT on anorectal function since deterioration of anorectal function occurs when PCRT is combined with SFS $[8,18,19]$.

With the above in mind, the objective of the present study was to exclude the effect of SPS in assessing the influence of PCRT on anorectal function by comparing changes after PCRT using anorectal manometry.

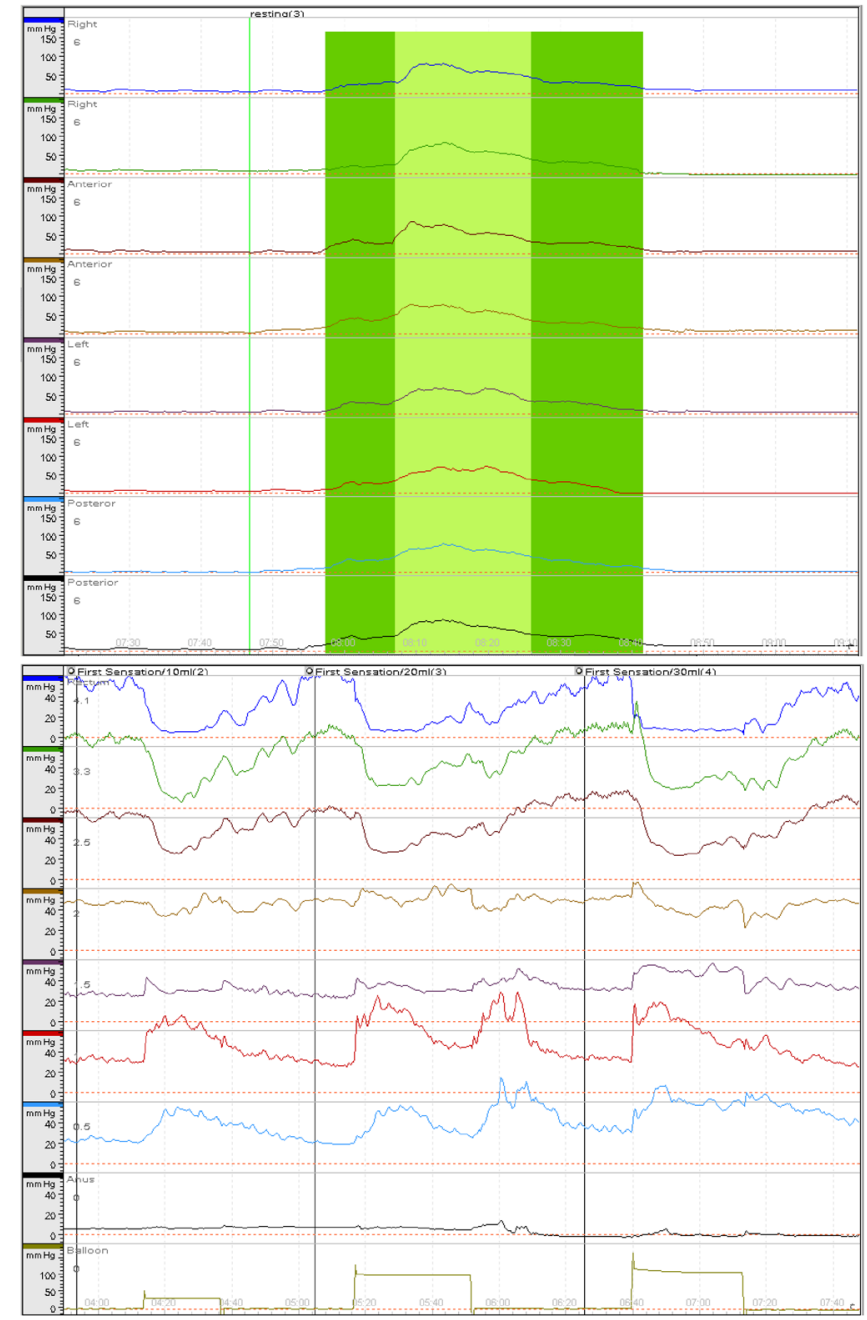

\section{RESULTS}

\section{Characteristics of patients}

The mean age of the 310 patients was $60.2 \pm 11.2$ years (range, 29-83 years). The male/female ratio was 2:1. The mean distance of the tumor from the anal verge (AV) was $4.48 \pm 1.36 \mathrm{~cm}$, and lower rectal cancer patients were predominant in the cohort. Upon clinical staging, 281 patients $(90.6 \%)$ were T3 and 229 patients $(73.9 \%)$ were N2. Tumors with moderate differentiation upon biopsy were the most common. Three patients had undergone temporary ileostomy before PCRT. The median dose of radiation was 50.4 Gy (50-50.4 Gy). The most frequently used concurrent chemotherapy agents were 5 -fluorouracil (FU) and leucovorin (LV) (Table 1).

Seventy-four patients $(23.9 \%)$ experienced one or more treatment-associated adverse effect, but there were

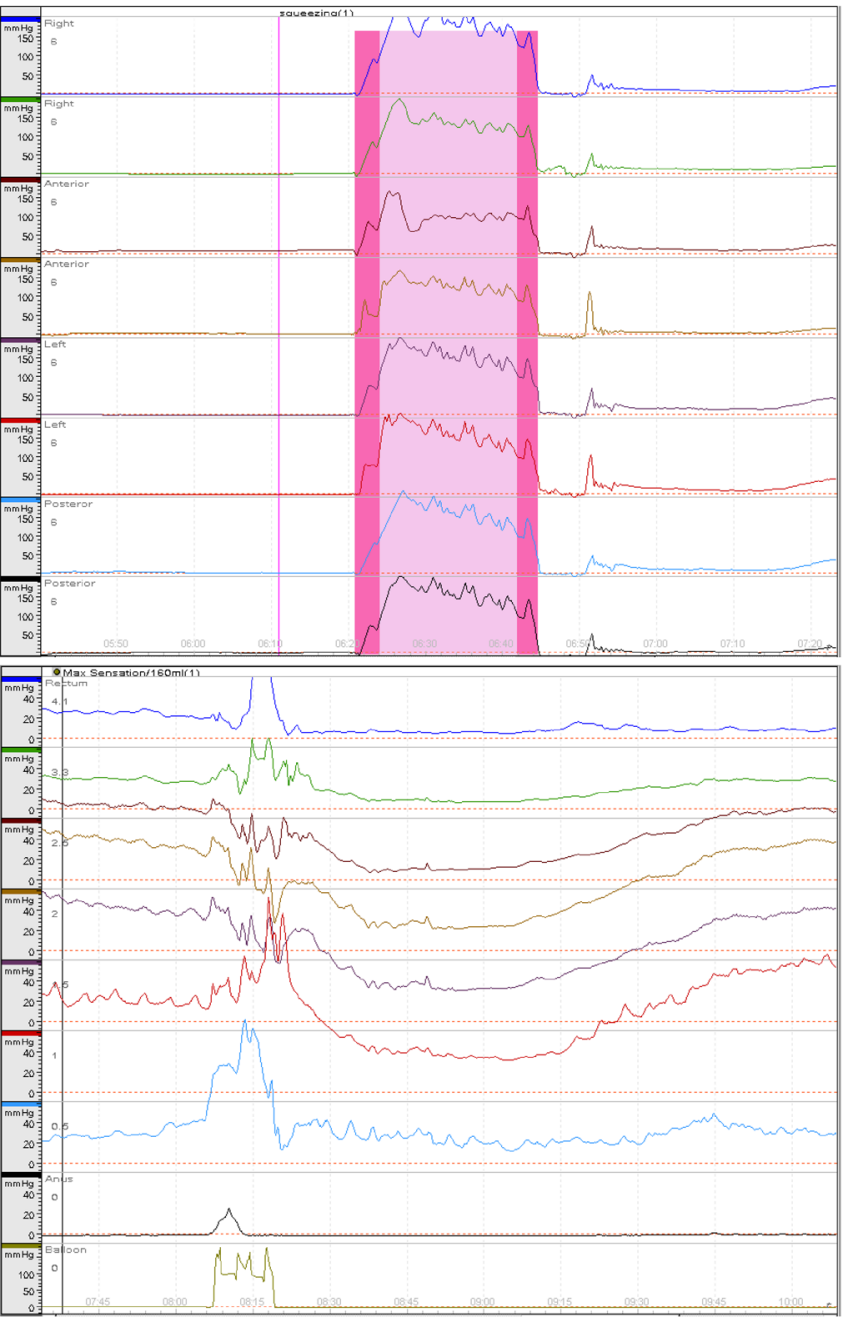

Figure 1: Anorectal manometry evaluation graph. Sphincter length, high pressure zone length, anal sphincter symmetry index, and maximal resting pressure (left top); maximal squeezing pressure (right top); minimal sensory volume and rectoanal inhibitory reflex (left bottom); urgent volume and maximal tolerated volume (right bottom). All measured using a hydraulic capillary infusion system. 
Table 1: General and clinical characteristics of patients

\begin{tabular}{|c|c|}
\hline Variables & Values, $n(\%)$ or mean $\pm \mathrm{SD}$ \\
\hline Age, years (range) & $60.2 \pm 11.2(29-83)$ \\
\hline \multicolumn{2}{|l|}{ Sex } \\
\hline Male & $207(66.8)$ \\
\hline Female & $103(33.2)$ \\
\hline Location of tumor, $\mathrm{cm}$ from $\mathrm{AV}$ & $4.48 \pm 1.36$ \\
\hline $\operatorname{LR}(\leq 5 \mathrm{~cm})$ & $228(73.5)$ \\
\hline $\operatorname{MR}(>5 \mathrm{~cm}, \leq 8 \mathrm{~cm})$ & $82(26.5)$ \\
\hline \multicolumn{2}{|l|}{ Clinical T stage } \\
\hline $\mathrm{T} 3$ & $281(90.6)$ \\
\hline $\mathrm{T} 4$ & $29(9.4)$ \\
\hline \multicolumn{2}{|l|}{ Clinical N stage } \\
\hline No & $10(3.2)$ \\
\hline $\mathrm{N}+$ & $300(96.8)$ \\
\hline \multicolumn{2}{|l|}{ Histologic differentiation } \\
\hline Well differentiated & $79(25.5)$ \\
\hline Moderately differentiated & $224(72.2)$ \\
\hline Poorly differentiated & $7(2.3)$ \\
\hline \multicolumn{2}{|l|}{ Clinical symptom } \\
\hline Hematochezia or Anal bleeding* & $251(81.0)$ \\
\hline Anal pain* & $45(14.5)$ \\
\hline Tenesmus* & $119(38.4)$ \\
\hline Stool caliber change* & $206(66.5)$ \\
\hline Number of defecations/day & $3.28 \pm 2.88$ \\
\hline Temporary Ileostomy & $3(1.0)$ \\
\hline Radiation dose, GY, mean (range) & $50.4(50-50.4)$ \\
\hline \multicolumn{2}{|l|}{ Concurrent chemotherapy } \\
\hline 5-FU + Leucovorin & $208(67.1)$ \\
\hline Capecitabine & $89(28.7)$ \\
\hline Capecitabine + Oxaliplatin & $13(4.2)$ \\
\hline
\end{tabular}

$\mathrm{AV}$ : anal verge, LR: lower rectum, MR: mid rectum, 5-FU: 5-fluorouracil

*multiple answers were included

no effects over grade 3 according to the Common Toxicity Criteria. Among the adverse effects, anal pain was the most common (35 patients [11.3\%]), followed by diarrhea in 11 patients $(3.5 \%)$, radiation dermatitis in 10 patients $(3.2 \%)$, nausea and vomiting in 10 patients $(3.2 \%)$, dysuria in nine patients $(2.9 \%)$, hand foot syndrome in six patients $(1.9 \%)$, radiation proctitis in six patients $(1.9 \%)$, constipation in three patients $(1.0 \%)$, stomatitis in two patients $(0.6 \%)$, and neurotoxicity in two patients $(0.6 \%)$.

\section{Changes in clinical characteristics between before and after PCRT}

After PCRT, the distance of the tumor from the AV increased significantly compared to that before PCRT. Among the 310 patients, the mean distance increased by $0.94 \pm 0.09 \mathrm{~cm}$ after PCRT in 143 patients (46.1\%), but it was unchanged in 109 patients $(35.2 \%)$ and decreased in 58 patients $(18.7 \%)$. Down-staging by magnetic resonance imaging (MRI) was observed in 100 patients $(32.3 \%)$. After PCRT, 32 patients $(10.3 \%)$ were down-staged in clinical T (cT) stage, 88 patients $(28.4 \%)$ were down- 
Table 2: Clinical characteristics between before and after PCRT

\begin{tabular}{|l|c|c|c|}
\hline \multicolumn{1}{|c|}{ Variables } & Before PCRT & After PCRT & $\boldsymbol{p}$-value \\
\hline Location of tumor, cm from AV & $4.48 \pm 1.36$ & $4.76 \pm 1.46$ & $<.001$ \\
\hline LR $(\leq 5 \mathrm{~cm})$ & $228(73.5)$ & $211(68.1)$ & .016 \\
\hline MR $(>5 \mathrm{~cm}, \leq 8 \mathrm{~cm})$ & $82(26.5)$ & $99(31.9)$ & \\
\hline Clinical T stage & & & \\
\hline T2 & $0(0.0)$ & $26(8.4)$ & $<.001$ \\
\hline T3 & $281(90.6)$ & $254(81.9)$ & \\
\hline T4 & $29(9.4)$ & $30(9.7)$ & \\
\hline Clinical N stage & & & \\
\hline N0 & $10(3.2)$ & $38(12.3)$ & $<.001$ \\
\hline N+ & $300(96.8)$ & $272(87.7)$ & \\
\hline Clinical symptom & & & \\
\hline Hematochezia or Anal bleeding* & $251(81.0)$ & $7(5.5)$ & $<.001$ \\
\hline Anal pain* & $45(14.5)$ & $92(29.7)$ & $<.001$ \\
\hline Tenesmus* & $119(38.4)$ & $37(11.9)$ & $<.001$ \\
\hline Stool caliber change* & $206(66.5)$ & $11(3.5)$ & $<.001$ \\
\hline Number of defecations/day & $3.28 \pm 2.88$ & $2.44 \pm 2.35$ & $<.001$ \\
\hline
\end{tabular}

PCRT: preoperative chemoradiotherapy, AV: anal verge, LR: lower rectum, MR: mid rectum

*multiple answers were included

staged in clinical $\mathrm{N}(\mathrm{cN})$ stage, and 20 patients $(6.5 \%)$ were down-staged in both $\mathrm{cT}$ and $\mathrm{cN}$ stage.

Among clinical symptoms, hematochezia or anal bleeding, tenesmus, and stool caliber decreased significantly at 4 weeks after the completion of PCRT, while anal pain increased significantly. The average number of defecations per day in the 307 patients (excluding three patients [1.0\%] who had undergone temporary ileostomy) decreased significantly after PCRT (Table 2).

\section{Changes in manometric parameters between before and after PCRT}

There were significant differences in sphincter length (SL), maximal resting pressure (MRP), and maximal tolerated volume (MTV) among the manometric parameters after PCRT. Maximal squeezing pressure (MSP) and rectal compliance slightly decreased without statistical significance (Figure 2).
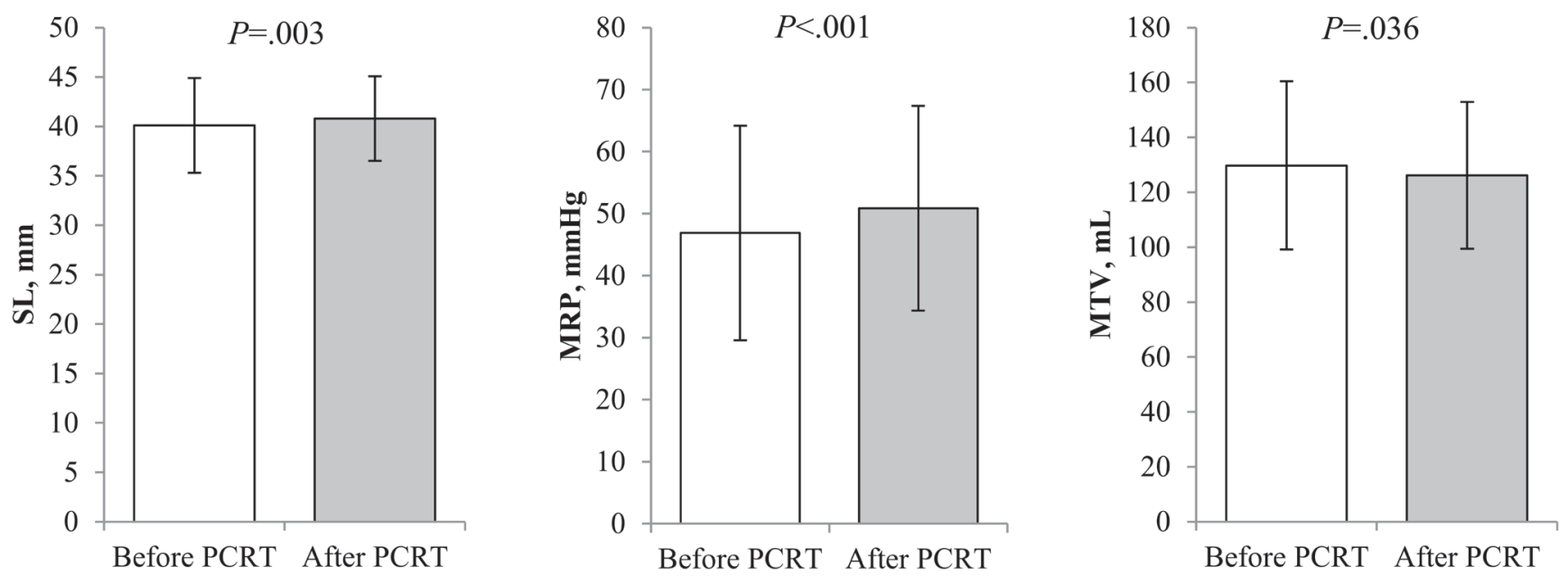

Figure 2: Comparison of manometric parameters between before and after preoperative chemoradiotherapy. Sphincter length $(40.1 \pm 4.8 v s .40 .8 \pm 4.3 \mathrm{~mm}, p=0.003)$ and maximal resting pressure $(46.88 \pm 17.29 \mathrm{vs} .50 .88 \pm 16.50 \mathrm{mmHg}, p<0.001) \mathrm{were}$ significantly increased after PCRT. Maximal tolerated volume decreased after PCRT (129.77 \pm 30.65 vs. $126.19 \pm 26.71 \mathrm{~mL}, p=0.036)$. 
Table 3: Comparison of manometric parameters between before and after PCRT according to tumor characteristics

\begin{tabular}{|c|c|c|c|c|c|c|c|c|c|c|c|c|}
\hline \multirow{3}{*}{ Variables } & \multicolumn{6}{|c|}{ Location of tumor } & \multicolumn{6}{|c|}{ Clinical T stage } \\
\hline & \multicolumn{3}{|c|}{$\mathrm{LR}(\leq 5 \mathrm{~cm})(n=228)$} & \multicolumn{3}{|c|}{$\operatorname{MR}(>5 \mathrm{~cm})(n=82)$} & \multicolumn{3}{|c|}{$\operatorname{cT3}(n=281)$} & \multicolumn{3}{|c|}{ cT4 $(n=29)$} \\
\hline & Before PCRT & After PCRT & $P$ & Before PCRT & After PCRT & $\boldsymbol{P}$ & Before PCRT & After PCRT & $\boldsymbol{P}$ & \begin{tabular}{|c|} 
Before \\
PCRT
\end{tabular} & After PCRT & $P$ \\
\hline $\mathrm{SL}^{*}$ & $4.00 \pm 0.49$ & $4.06 \pm 0.44$ & .020 & $4.05 \pm 0.43$ & $4.13 \pm 0.42$ & .044 & $3.98 \pm 0.46$ & $4.08 \pm 0.43$ & $<.001$ & $4.26 \pm 0.56$ & $4.13 \pm 0.46$ & .217 \\
\hline $\mathrm{HPZ}^{*}$ & $2.22 \pm 0.62$ & $2.26 \pm 0.58$ & .391 & $2.24 \pm 0.57$ & $2.19 \pm 0.61$ & .554 & $2.22 \pm 0.60$ & $2.25 \pm 0.59$ & .385 & $2.30 \pm 0.68$ & $2.13 \pm 0.56$ & .285 \\
\hline $\mathrm{MRP}^{+}$ & $46.86 \pm 17.64$ & $50.83 \pm 16.23$ & $<.001$ & $46.95 \pm 16.38$ & $51.02 \pm 11.53$ & .012 & $45.10 \pm 10.07$ & $50.43 \pm 16.39$ & $<.001$ & $58.33 \pm 19.23$ & $55.29 \pm 17.23$ & .325 \\
\hline $\mathrm{MSP}^{+}$ & $178.64 \pm 94.43$ & $170.59 \pm 70.68$ & .126 & $175.36 \pm 70.95$ & $178.81 \pm 67.51$ & .523 & $174.67 \pm 89.80$ & $170.84 \pm 68.37$ & .380 & $207.88 \pm 72.03$ & $191.33 \pm 81.80$ & 198 \\
\hline ASI & $0.80 \pm 0.08$ & $0.81 \pm 0.66$ & .652 & $0.80 \pm 0.07$ & $0.81 \pm 0.07$ & .132 & $0.80 \pm 0.08$ & $0.80 \pm 0.07$ & .489 & $0.81 \pm 0.07$ & $0.84 \pm 0.07$ & .129 \\
\hline $\mathrm{MSV}^{\S}$ & $10.79 \pm 3.01$ & $10.57 \pm 2.32$ & .385 & $10.49 \pm 2.17$ & $10.00 \pm 0.00$ & .045 & $10.71 \pm 2.84$ & $10.39 \pm 1.94$ & .128 & $10.69 \pm 2.58$ & $10.69 \pm 2.58$ & 1.00 \\
\hline UV \$ & $59.34 \pm 9.00$ & $59.21 \pm 6.37$ & .841 & $59.88 \pm 9.88$ & $59.82 \pm 6.78$ & .962 & $59.79 \pm 9.29$ & $59.48 \pm 6.63$ & .630 & $56.55 \pm 8.14$ & $58.28 \pm 4.68$ & .283 \\
\hline MTV & $127.61 \pm 30.91$ & $125.42 \pm 26.06$ & .233 & $135.79 \pm 29.28$ & $128.35 \pm 28.48$ & .062 & $130.55 \pm 30.70$ & $126.90 \pm 26.62$ & .048 & $122.24 \pm 29.69$ & $119.31+27.05$ & $\therefore 68$ \\
\hline $\mathrm{RC}^{\mathcal{L}}$ & $1.65 \pm 1.40$ & $1.47 \pm 1.23$ & .137 & $1.64 \pm 1.03$ & $1.49 \pm 0.91$ & .288 & $1.63 \pm 1.13$ & $1.47 \pm 1.18$ & $\begin{array}{l}\cdots \\
.077\end{array}$ & $1.79 \pm 2.46$ & $1.56 \pm 0.86$ & .640 \\
\hline RAIR & 92.1 & 94.7 & .286 & 92.7 & 96.3 & .375 & $\dddot{91.5}$ & 95.0 & .076 & 100 & 96.6 & \\
\hline
\end{tabular}

${ }^{*} \mathrm{~cm},{ }^{+} \mathrm{mmHg},{ }^{8} \mathrm{~mL} ;{ }^{\star}{ }^{\star}-\mathrm{mL} / \mathrm{mmHg}, \boldsymbol{\uparrow} \%$

PCRT: preoperative chemoradiotherapy, LR: lower rectum, MR: mid rectum, SL: sphincter length, HPZ: high pressure zone, MRP: maximal resting pressure, MSP: maximal squeezing pressure, ASI: anal sphincter symmetry index, MSV: minimal sensory volume, MTV: maximal tolerated volume, UV: urgent volume, RC: rectal compliance, RAIR: rectoanal inhibitory reflex

When comparing the differences in the location of the tumors, the SL and MRP increased significantly in both lower and mid rectal cancers. While the MTV and rectal compliance slightly decreased, these differences were not statistically significant. Changes between manometric parameters before and after PCRT were not associated with the location of tumor. When comparing changes in the clinical stages of the tumors, SL and MRP showed significant increases while MTV decreased significantly after PCRT in cT3 rectal cancers. However, there were no significant changes in cT4 rectal cancers between before and after PCRT (Table 3).

We investigated changes in manometric parameters according to the changes in distance from the $\mathrm{AV}$ and $\mathrm{cT}$ stage after PCRT. Minimal sensory volume (MSV) and MTV increased significantly in 143 patients (46.1\%) who had greater distance of the tumor from the AV after PCRT. However, in patients with no increase in distance or a smaller distance of the tumor from the AV after PCRT, MSV and MTV showed significant decreases after PCRT. There were no significant differences in manometric parameters after PCRT according to down-staging in $\mathrm{cT}$ stage after PCRT (Table 4).

\section{DISCUSSION}

The present study compared the results from before and after PCRT with the objective of assessing the direct influence of PCRT on anorectal function, for which changes in manometric parameters were observed as comparisons of objective indices. In addition, subgroup analysis was conducted to examine whether anorectal function is affected by changes in the clinical features of tumors after PCRT. According to the findings of the present study, anorectal manometry after PCRT revealed significant increases in SL and MRP and decreases in MTV.

There are varying reports regarding the changes in manometric parameters between before and after PCRT. In some studies [19, 20], SL increased as in the present study. In terms of pressure profiles, there have been contradictory reports [3,20-22]. De Nardi et al. [22] reported that $23 \%$ of patients, showed the new onset of anorectal dysfunctions, mostly represented by a lower MRP after PCRT. They explained that it caused by radiation damage to the internal anal sphincter muscles. On the contrary, another study [20] reported increase in MRP after PCRT and we also showed increase in MRP after PCRT . There have been various hypotheses about radiation effect on defecatory function such as damage to anal sphincter injury, pudendal nerve, and reduced distensibility of the neo-rectum [15]. However, there was no clear explanation. Based on the results of the present study, radiation effect would not be detrimental to internal anal sphincter. Radiation effect on defecatory function was not mainly caused by sphincter damage but change in distensibility according to our results.

In the present study, a significant decrease in MTV was found subsequent to PCRT. Some studies $[3,19,20]$ reported decreases in MTV after PCRT, but the differences were not statistically significant. Although some have also reported a decrease in rectal compliance [20], the present study did not find such a difference. Edema [20, $21]$ and acute inflammation $[19,21]$ in the anal and rectal mucosa caused by PCRT may cause pain in the anus and rectum, which may lead to increased tension in the internal anal sphincter and anorectal sensitivity, leading to changes in pressure or volume. However, such changes are not reported consistently. Such differences may arise from differences between patient groups, as well as the assessment methods and periods used in each study. 
Table 4: Comparison of the differences in manometric parameters between before and after PCRT according to tumor response to PCRT

\begin{tabular}{|c|c|c|c|c|c|c|}
\hline \multirow[b]{2}{*}{ Variables } & \multicolumn{3}{|c|}{ Tumor distance from the anal verge } & \multicolumn{3}{|c|}{ Clinical T stage } \\
\hline & $\begin{array}{c}\text { No increase } \\
(n=167)\end{array}$ & $\begin{array}{l}\text { Increase } \\
(n=143)\end{array}$ & $p$-value & $\begin{array}{c}\text { Not reduced } \\
(n=278)\end{array}$ & $\begin{array}{c}\text { Reduced } \\
(n=32)\end{array}$ & $p$-value \\
\hline $\mathrm{SL}, \mathrm{cm}$ & $0.07 \pm 0.46$ & $0.08 \pm 0.40$ & .795 & $0.07 \pm 0.44$ & $0.08 \pm 0.39$ & .967 \\
\hline HPZ length, cm & $-0.01 \pm 0.71$ & $0.05 \pm 0.68$ & .511 & $0.04 \pm 0.69$ & $-0.17 \pm 0.74$ & .127 \\
\hline $\mathrm{MRP}, \mathrm{mmHg}$ & $4.03 \pm 14.26$ & $3.95 \pm 13.19$ & .959 & $4.04 \pm 13.82$ & $3.55 \pm 13.41$ & .853 \\
\hline MSP, mmHg & $-5.16 \pm 89.66$ & $-4.85 \pm 45.06$ & .970 & $-6.59 \pm 74.49$ & $9.63 \pm 48.41$ & .245 \\
\hline ASI & $0.01 \pm 0.09$ & $0.01 \pm 0.08$ & .983 & $0.00 \pm 0.08$ & $0.04 \pm 0.13$ & .118 \\
\hline $\mathrm{MSV}, \mathrm{mL}$ & $-0.66 \pm 3.66$ & $0.14 \pm 3.14$ & .042 & $-0.11 \pm 2.99$ & $-2.00 \pm 6.10$ & .104 \\
\hline Urgent volume, $\mathrm{mL}$ & $-0.69 \pm 10.70$ & $0.56 \pm 9.91$ & .290 & $-0.02 \pm 10.81$ & $-1.00 \pm 4.23$ & .622 \\
\hline MTV, mL & $-7.10 \pm 30.00$ & $0.52 \pm 29.56$ & .025 & $-4.07 \pm 30.47$ & $1.00 \pm 25.00$ & .380 \\
\hline Rectal compliance, $\mathrm{mL} / \mathrm{mmHg}$ & $-0.29 \pm 2.02$ & $-0.03 \pm 1.07$ & .174 & $-0.16 \pm 1.50$ & $-0.26 \pm 2.83$ & .869 \\
\hline
\end{tabular}

SL: sphincter length, HPZ: high pressure zone, MRP: maximal resting pressure, MSP: maximal squeezing pressure, ASI: anal sphincter symmetry index, MSV: minimal sensory volume, MTV: maximal tolerated volume

However, the change in distensibility of neo-rectum may cause anorectal dysfunction after PCRT.

There have been attempts to compare the differences in anorectal function between before and after PCRT based on the location of the tumor. While one study [20] reported differences based on location when rectal cancer was differentiated as either lower and mid rectal cancer, other studies reported no differences in anorectal function $[19,21]$. The present study also found no significant differences based on the location of the tumor, which is believed to be the result of both lower and mid rectal cancers being included in the radiation field. Furthermore, when any deterioration due to surgery was excluded, outcomes after PCRT did not vary based on the location of the tumor.

With respect to anorectal function after PCRT based on cT stages, significant increases in SL $(p<0.001)$ and MRP $(p<0.001)$ and significant decreases in MTV $(p=0.048)$ were found after PCRT in cT3 rectal cancer cases. However, there were no significant differences in anorectal function after PCRT in cT4 rectal cancer cases. It is believed that such differences may be attributable to the difference in sample size between cT3 $(n=281$, $90.6 \%)$ and cT4 $(n=29,9.4 \%)$ cases. However, some studies reported that tumor response to PCRT becomes worse in high cT stages [23-25]. Therefore, the possibility of changes in anorectal function based on cT stage being caused by such differences in responsiveness can also be suspected. In fact, among the participants in the present study, total regression was found in $45.2 \%$ of cT3 patients, which was higher than the $31.0 \%$ noted in cT4 patients.
However, because of the difference in sample size between cT3 and cT4 rectal cancer cases, additional studies are needed to generalize the findings.

The changes in the distance of the tumor from the $\mathrm{AV}$ and cT stages after PCRT can be used as indirect indicators of tumor response to PCRT. The present study examined whether differences in tumor response to PCRT can cause changes in anorectal function based on indirect indicators. In patients who showed increased distance from the AV to the tumor after PCRT, there were significant increases in MSV and MTV, whereas in patients who showed no change or a decrease in the distance from the AV to the tumor, MSV and MTV decreased after PCRT. The former may be attributed to a decrease in tumor size. In the present study, there was no significant difference in anorectal function after PCRT based on changes in $\mathrm{cT}$ stage. Contrary to the findings in the present study, Kye et al. [19] showed significant increases in the length of the high pressure zone (HPZ) and urgent volume in downstaging of cT stage after PCRT. They claimed that such results were not attributable to improved rectal sensation, such as urgent volume, after PCRT in rectal cancer patients with down-staging cT stage, but rather due to exacerbation after PCRT in rectal cancer cases that did not show downstaging of cT stage. Due to the lack of accuracy in the evaluation of cT staging, it is believed that differences between studies may arise from difficulties in assessing actual responses to radiation by changes in $\mathrm{cT}$ stages.

In this study, clinical symptoms at 4 weeks after the completion of PCRT were mostly improved, but anal pain alone was significantly increased. Since anal pain may be 
caused by anal or rectal mucosal edema or ulceration from vasculitis near the tumor, as well as improved symptoms from a reduction in tumor size, these are also factors that may affect anorectal manometry and should be assessed as factors that affect anorectal function after radiation therapy. Based on the findings of the present study, MTV decreased after PCRT, but that decrease amounted to only $2.8 \%$ as compared to before PCRT, meaning that the difference was minimal. Meanwhile, there were no significant differences in rectal compliance and RAIR after PCRT, meaning that those factors may not have any short-term effects on exacerbating anorectal function. We only evaluated the anorectal dysfunction after PCRT using anorectal manometric finding. However, operative complications after PCRT such as anastomotic leakage may be associated with functional outcomes. In the present study, only $1 \%$ of patients received temporary diversion and leakage rate was less than $3 \%$, therefore, the effect of complications and diversion on defecatory function would not be statistically evaluated. But, we need to consider these practical factors assessing the functional outcomes after PCRT.

Anorectal function after PCRT was similar regardless of the distance of the tumor from the $\mathrm{AV}$, but there is a limitation in the interpretation of anorectal function according to cT stage due to differences in sample size. The anorectal function, however, have to be evaluated after definitive surgery because it would also influence on anorectal function. Indeed, the long-term effect of PCRT also has to be evaluated because anorectal function might be changed after definitive surgery and long term follow-up. This study included a relatively large sample of 310 patients with rectal cancer. However, this was a retrospective study. As such, it was limited because we were not able to use systematic assessment tools to measure fecal incontinence, constipation, and quality of life after PCRT. Further study is required to investigate postoperative anorectal function after SPS to evaluate the long-term influence of PCRT on anorectal function.

\section{MATERIALS AND METHODS}

\section{Patients and preoperative chemoradiotherapy}

We retrospectively reviewed 310 patients with locally advanced rectal cancer who underwent PCRT from January 2012 to May 2015 at Asan Medical Center. The participants were patients who had undergone anorectal manometry before and after PCRT and met the follow inclusion criteria: definitive diagnosis of adenocarcinoma from a biopsy, the tumor was located within $8 \mathrm{~cm}$ from the $\mathrm{AV}$, and the tumor invasion level was T3-T4 or lymph-node metastasis was suspected on MRI. Tumor distance from the AV was measured using the curvilinear measurement on MRI by drawing multiple linear lines along the approximate luminal center of the rectum and the anus on the midline sagittal plane as recommended by a national recommendation. We excluded patients who were diagnosed with distant metastasis, had a history of radiotherapy or chemotherapy, could not complete PCRT, and were not available for anorectal manometry before and after PCRT. Rectal cancer was classified as either lower or mid rectal depending on the tumor being located $\leq 5 \mathrm{~cm}$ or $>5 \mathrm{~cm}$ to $\leq 8 \mathrm{~cm}$ from the $\mathrm{AV}$, respectively. Patients received radiotherapy with $1.8-2.0$ Gy per fraction at a total dose of 50-50.4 Gy in 25 28 fractions using a 3 or 4-field technique. Concurrent chemotherapy was provided with an intravenous bolus of 5-FU and LV for $3 \mathrm{~d}$ after the beginning of radiotherapy and for $3 \mathrm{~d}$ before the end of radiotherapy, or with oral capecitabine twice daily during the treatment period.

This study was approved by the Institutional Review Board of the Asan Medical Center (authorization number 2016-0245).

\section{Anorectal manometry}

Anorectal manometry was performed before PCRT and 4-8 weeks (mean, $5.96 \pm 0.95$ weeks) after the completion of PCRT. A hydraulic capillary infusion system (Polygraf ID, Medtronic, Denmark) was used with the pull-through technique, and the perfusion catheter was an 8-channel polyethylene flexible catheter with an outer diameter of $5.5 \mathrm{~mm}$ and a total length of $150 \mathrm{~cm}$. A radial perfusion catheter was inserted so that the channel of the catheter would be positioned $6 \mathrm{~cm}$ from the AV. Subsequently, the SL, HPZ, MRP, and anal sphincter symmetry index (ASI) were measured while retracting with an automatic puller for $1 \mathrm{~min}$ at a constant rate of $1 \mathrm{~mm} / \mathrm{sec}$. After three repeated measurements under stable conditions, the catheter was reinserted and MSP was measured while squeezing the anal sphincter as much as possible in the HPZ while the catheter was being retracted continuously. A spiral perfusion catheter with a latex balloon attached at its end was inserted so that the \#8 channel would be positioned on the AV. Subsequently, MSV, urgent volume, and MTV were measured as the latex balloon was inflated with a syringe, while at the same time checking for RAIR. The system-embedded software program (Polygram, USA) calculated SL, length of HPZ, MRP, MSP, ASI, and rectal pressure based on the measured pressure values, while rectal compliance was calculated based on the volume of the inflated air and rectal pressure (Figure 1). Anorectal manometry was performed by two nurses with more than 10,000 cases of experience with this procedure. 


\section{Statistical analysis}

We compared manometric parameters between before and after PCRT according to tumor characteristics, such as the location of the tumor, cT stage, and tumor response after PCRT. We measured the differences in manometric parameters between before and after PCRT, expressing increases as positive values and decreases as negative values. Quantitative manometric parameters except RAIR were expressed as the mean $\pm \mathrm{SD}$. Clinical characteristics except the number of defecations between before and after PCRT were compared using the chi-square test (McNemar test). The paired t-test and chi-square test (McNemar test) were used to compare manometric parameters between before and after PCRT. Statistical analyses were performed using SPSS version 22.0 (IBM Statistics, Armonk, NY). $p$-values $<0.05$ were considered statistically significant.

\section{Abbreviations}

PCRT: preoperative chemoradiotherapy; SPS: sphincter-preserving surgery; $\mathrm{AV}$ : anal verge; $\mathrm{SL}$ : sphincter length; HPZ: high pressure zone; MRP: maximal resting pressure; ASI: and anal sphincter symmetry index ASI; MTV: maximal tolerated volume; MSV: minimal sensory volume; MSP: maximal squeezing pressure; RAIR: rectoanal inhibitory reflex; FU: fluorouracil; LV: leucovorin.

\section{Author contributions}

Jin Sook Song: study design, data collection, writing the manuscript, and confirmation of the manuscript.

In Ja Park and Jeong Hye Kim: study design, data collection, and confirmation of the manuscript.

Hyang Ran Lee and Jeong Rang Kim: data collection.

Jong Lyul Lee, Yong Sik Yoon, Chan Wook Kim, Seok-Byung Lim, Chang Sik Yu, and Jin Cheon Kim: data collection and confirmation of manuscript.

\section{CONFLICTS OF INTEREST}

The authors have declared no conflicts of interest.

\section{REFERENCES}

1. Ammann K, Kirchmayr W, Klaus A, Muhlmann G, Kafka R, Oberwalder M, De Vries A, Ofner D, Weiss H. Impact of neoadjuvant chemoradiation on anal sphincter function in patients with carcinoma of the midrectum and low rectum. Arch Surg. 2003; 138:257-261.

2. Crane $\mathrm{CH}$, Skibber J. Preoperative chemoradiation for locally advanced rectal cancer: rationale, technique, and results of treatment. Semin Surg Oncol. 2003; 21:265-270.

3. Canda AE, Terzi C, Gorken IB, Oztop I, Sokmen S, Fuzun M. Effects of preoperative chemoradiotherapy on anal sphincter functions and quality of life in rectal cancer patients. Int J Colorectal Dis. 2010; 25:197-204.

4. Colorectal Cancer Collaborative Group. Adjuvant radiotherapy for rectal cancer: a systematic overview of 8,507 patients from 22 randomised trials. Lancet. 2001; 358:1291-1304.

5. Sauer R, Becker H, Hohenberger W, Rodel C, Wittekind C, Fietkau R, Martus P, Tschmelitsch J, Hager E, Hess CF, Karstens JH, Liersch T, Schmidberger H, et al. Preoperative versus postoperative chemoradiotherapy for rectal cancer. N Engl J Med. 2004; 351:1731-1740.

6. Bosset JF, Collette L, Calais G, Mineur L, Maingon P, Radosevic-Jelic L, Daban A, Bardet E, Beny A, Ollier JC, EORTC Radiotherapy Group Trial 22921. Chemotherapy with preoperative radiotherapy in rectal cancer. N Engl J Med. 2006; 355:1114-1123.

7. Kapiteijn E, Marijnen CA, Nagtegaal ID, Putter H, Steup WH, Wiggers T, Rutten HJ, Pahlman L, Glimelius B, van Krieken JH, Leer JW, van de Velde CJ, Dutch Colorectal Cancer Group. Preoperative radiotherapy combined with total mesorectal excision for resectable rectal cancer. $\mathrm{N}$ Engl J Med. 2001; 345:638-646.

8. Bryant CL, Lunniss PJ, Knowles CH, Thaha MA, Chan CL. Anterior resection syndrome. Lancet Oncol. 2012; 13:e403408.

9. Kim NK. Recent advances in the diagnosis and treatment for rectal cancer. J Korean Med Assoc. 2003; 46:620-628.

10. Lorenzi B, Brading AF, Martellucci J, Cetta F, Mortensen NJ. Short-term effects of neoadjuvant chemoradiotherapy on internal anal sphincter function: a human in vitro study. Dis Colon Rectum. 2012; 55:465-472.

11. Bregendahl S, Emmertsen KJ, Lous J, Laurberg S. Bowel dysfunction after low anterior resection with and without neoadjuvant therapy for rectal cancer: a population-based cross-sectional study. Colorectal Dis. 2013; 15:1130-1139.

12. Gervaz P, Rotholtz N, Pisano M, Kaplan E, Secic M, Coucke P, Pikarsky A, Efron J, Weiss E, Wexner S. Quantitative short-term study of anal sphincter function after chemoradiation for rectal cancer. Arch Surg. 2001; 136:192-196.

13. Matzel KE, Bittorf B, Gunther K, Stadelmaier U, Hohenberger W. Rectal resection with low anastomosis: functional outcome. Colorectal Dis. 2003; 5:458-464.

14. Parc Y, Zutshi M, Zalinski S, Ruppert R, Furst A, Fazio VW. Preoperative radiotherapy is associated with worse functional results after coloanal anastomosis for rectal cancer. Dis Colon Rectum. 2009; 52:2004-2014.

15. Lim JF, Tjandra JJ, Hiscock R, Chao MW, Gibbs P. Preoperative chemoradiation for rectal cancer causes prolonged pudendal nerve terminal motor latency. Dis 
Colon Rectum. 2006; 49:12-19.

16. Pietsch AP, Fietkau R, Klautke G, Foitzik T, Klar E. Effect of neoadjuvant chemoradiation on postoperative fecal continence and anal sphincter function in rectal cancer patients. Int J Colorectal Dis. 2007; 22:1311-1317.

17. Ozgen Z, Ozden S, Atasoy BM, Ozyurt H, Gencosmanoglu $\mathrm{R}$, Imeryuz $\mathrm{N}$. Long-term effects of neoadjuvant chemoradiotherapy followed by sphincter-preserving resection on anal sphincter function in relation to quality of life among locally advanced rectal cancer patients: a crosssectional analysis. Radiat Oncol. 2015; 10:168.

18. Bittorf B, Stadelmaier U, Gohl J, Hohenberger W, Matzel KE. Functional outcome after intersphincteric resection of the rectum with coloanal anastomosis in low rectal cancer. Eur J Surg Oncol. 2004; 30:260-265.

19. Kye BH, Kim HJ, Kim JG, Kim SH, Shim BY, Lee NS, Cho HM. Short-term effects of neoadjuvant chemoradiation therapy on anorectal function in rectal cancer patients: a pilot study. Radiat Oncol. 2013; 8:203.

20. Jang NY, Han TJ, Kang SB, Kim DW, Kim IA, Kim JS. The short-term effect of neoadjuvant chemoradiation on anorectal function in low and midrectal cancer: analysis using preoperative manometric data. Dis Colon Rectum. 2010; 53:445-449.
21. Birnbaum EH, Dreznik Z, Myerson RJ, Lacey DL, Fry RD, Kodner IJ, Fleshman JW. Early effect of external beam radiation therapy on the anal sphincter: a study using anal manometry and transrectal ultrasound. Dis Colon Rectum. 1992; 35:757-761.

22. De Nardi P, Testoni SG, Corsetti M, Andreoletti H, Giollo P, Passaretti S, Testoni PA. Manometric evaluation of anorectal function in patients treated with neoadjuvant chemoradiotherapy and total mesorectal excision for rectal cancer. Dig Liver Dis. 2017; 49:91-9723.

23. Kalady MF, de Campos-Lobato LF, Stocchi L, Geisler DP, Dietz D, Lavery IC, Fazio VW. Predictive factors of pathologic complete response after neoadjuvant chemoradiation for rectal cancer. Ann Surg. 2009; 250:582589.

24. Martin ST, Heneghan HM, Winter DC. Systematic review and meta-analysis of outcomes following pathological complete response to neoadjuvant chemoradiotherapy for rectal cancer. Br J Surg. 2012; 99:918-928.

25. Pucciarelli S, Toppan P, Friso ML, Russo V, Pasetto L, Urso E, Marino F, Ambrosi A, Lise M. Complete pathologic response following preoperative chemoradiation therapy for middle to lower rectal cancer is not a prognostic factor for a better outcome. Dis Colon Rectum. 2004; 47:1798-1807. 